\title{
HIV testing: changing trends at a clinic for sexually transmitted diseases in London
}

\author{
E J BECK, D G CUNNINGHAM, V W MOSS, J R W HARRIS, A J PINCHING, \\ D J JEFFRIES
}

\begin{abstract}
Trends in human immunodeficiency virus (HIV) counselling and antibody testing at a London clinic for sexually transmitted diseases showed substantial changes over a 12 month period. From around 100 a month in the summer of 1986 the numbers of people attending rose substantially to 276 in October 1986 and 475 in November at the time of the campaign in the popular press. They rose further still, to 700, at the time of AIDS (acquired immune deficiency syndrome) week in March 1987. In April they fell to the levels seen six months previously. Apart from this increase in overall numbers the proportions of women and heterosexual men who were seen increased.
\end{abstract}

\section{Introduction}

Since October 1985 testing for the human immunodeficiency virus (HIV) has been available for routine clinical use. The public's awareness in Britain of HIV infection has recently been heightened by an increasingly effective media campaign. This paper describes some of the changing patterns of HIV testing as observed at a busy

St Mary's Hospital and Medical School, London W2 1NY

E J BECK, MB, BS, registrar, department of community medicine D G CUNNINGHAM, MFCM, head, department of community medicine

$\mathrm{V} W$ MOSS, SRN, manager health adviser, Praed Street Clinic, departments of community and genitourinary medicine

J R W HARRIS, FRCP, head of department of genitourinary medicine

A J PINCHING, FRCP, senior lecturer, department of clinical immunology

D J JEFFRIES, FRCPATH, head of division of virology, department of medical microbiology

Correspondence to: Dr Beck.
London clinic for sexually transmitted diseases over a 12 month period from December 1985 to November 1986, with numerical data to April 1987.

\section{Methods}

Data were collected by monitoring patients who voluntarily attended the clinic for HIV counselling and testing: the survey population was therefore self selected. The study period covered the 12 months from 1 December 1985 to 30 November 1986, and data were initially collected by sex and HIV test result. This was extended in June to include sexual preference and stated address, though strict confidentiality was maintained. Data were also obtained from health advisers concerning patients whom they had counselled at the clinic.

All patients who attended the clinic and requested HIV testing received counselling before and after the test in one of two ways. Patients who were seen by a junior doctor (senior house officer or registrar) were referred to a health adviser for counselling. The health adviser also gave post-test counselling. The senior medical staff (senior registrar, consultants) gave their own counselling.

HIV tests were performed in the division of virology by using commercially available tests. A competitive enzyme linked immunosorbent assay (ELISA) (Wellcome) was used as an initial screening test. All positive results were checked by an antibody capture ELISA (Abbott).

\section{Results}

During the study 63102 patient visits were recorded at the clinic, $57 \%$ men and $43 \%$ women. This compares with $64500(60 \%$ men and $40 \%$ women) in the preceding 12 months. The total number of monthly attendances did not vary greatly. Of the total number of visits'; $62 \%$ were new and $38 \%$ follow ups, which was similar for the preceding 12 months. The male to female ratio was 1.3:1 and remained constant over the two years. A total of $1782 \mathrm{HIV}$ tests were performed during the study, of which $190(11 \%)$ were positive. The number of tests performed per month remained relatively 
constant until October 1986. During October and November there was an appreciable increase in the number of tests performed (fig 1), with 754 patients tested, $42 \%$ of the years's total. This increase persisted after the end of the study period (fig 2). Overall the male to female ratio was 3:1, but a monthly variation was observed; whereas in December $198513 \%$ of those tested were women, by November 1986 this had increased to $36 \%$. Of all women tested $(n=441), 58 \%$ were seen during October and November compared with $37 \%$ of the men $(n=1341)$.

Of the 190 seropositive patients, all but three were men. Although there was an absolute increase in the number of positive tests as more people were tested, the proportion of those positive for HIV decreased from $21 \%$ in December to $6 \%$ in November. Of those patients who were asked about their sexual behaviour ( $\mathrm{n}=1158), 52 \%$ were heterosexual, $37 \%$ homosexual (men) and $11 \%$ bisexual (men). Though the absolute numbers of patients who were tested increased in all three groups, the percentage of heterosexuals who were tested increased to $70 \%$ during the last three months, but of the 102 seropositive patients whose sexual orientation was known, 82 were homosexuals (table).

Of all patients tested whose address was known $(n=1131), 94 \%$ resided in the four Thames health regions. North West Thames residents accounted for $50 \%$, of whom $37 \%$ lived in the Paddington and North Kensington

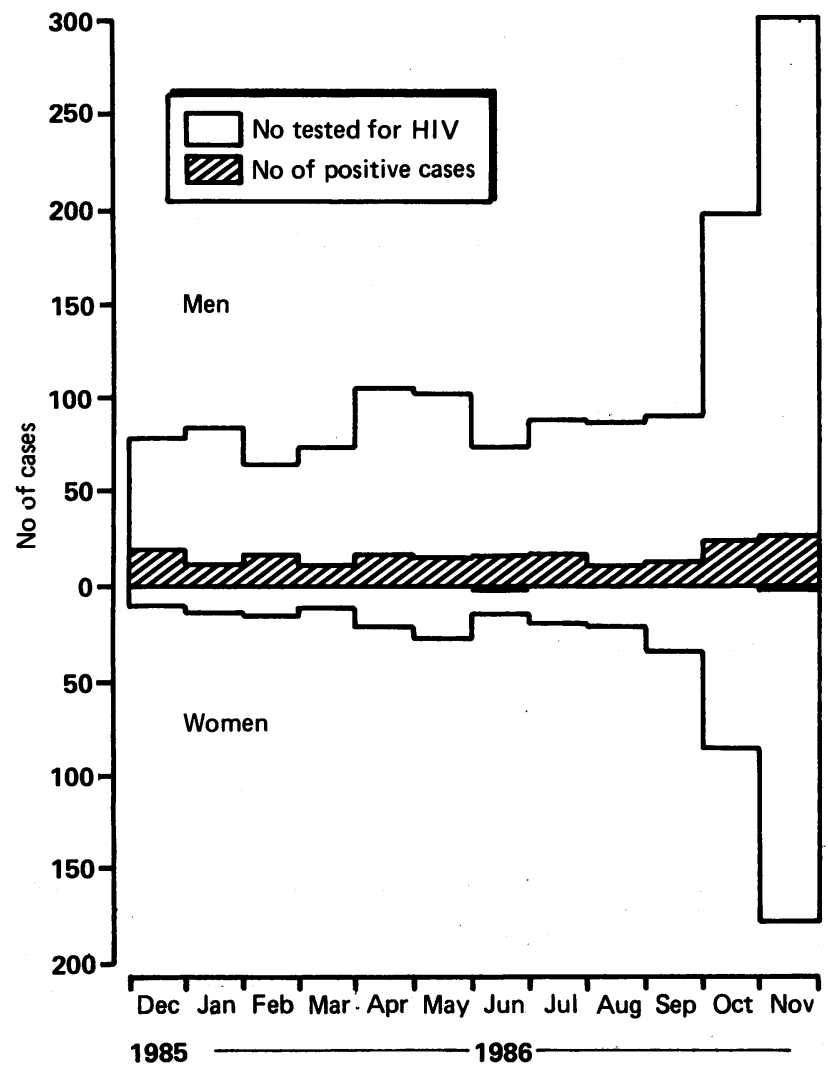

FIG 1-Distribution by month of the number of men and women who were tested for HIV. Hatched area shows the positive cases.

Number of patients over six months who requested a test for HIV and their stated sexual orientation

\begin{tabular}{|c|c|c|c|c|c|c|c|c|}
\hline \multirow[b]{3}{*}{1986} & \multicolumn{8}{|c|}{ Patient's stated sexual orientation } \\
\hline & \multicolumn{2}{|c|}{ Total } & \multicolumn{2}{|c|}{ Homosexual } & \multicolumn{2}{|c|}{ Heterosexual } & \multicolumn{2}{|c|}{ Bisexual } \\
\hline & No & $\begin{array}{c}\text { No } \\
\text { positive }\end{array}$ & No & $\begin{array}{c}\text { No } \\
\text { positive }\end{array}$ & No & $\begin{array}{c}\text { No } \\
\text { positive }\end{array}$ & No & $\begin{array}{c}\text { No } \\
\text { positive }\end{array}$ \\
\hline June & 80 & 14 & 49 & 11 & 21 & 2 & 10 & 1 \\
\hline July & 103 & 15 & 57 & 14 & 32 & - & 14 & 1 \\
\hline August & 105 & 9 & 46 & 6 & 34 & 2 & 25 & i \\
\hline September & 119 & 13 & 52 & 11 & 51 & 1 & 16 & 1 \\
\hline October & 276 & 22 & 103 & 15 & 146 & 6 & 27 & 1 \\
\hline November & 475 & 29 & 124 & 25 & 321 & 4 & 30 & - \\
\hline Total & 1158 & 102 & 431 & 82 & 605 & 15 & 122 & 5 \\
\hline
\end{tabular}

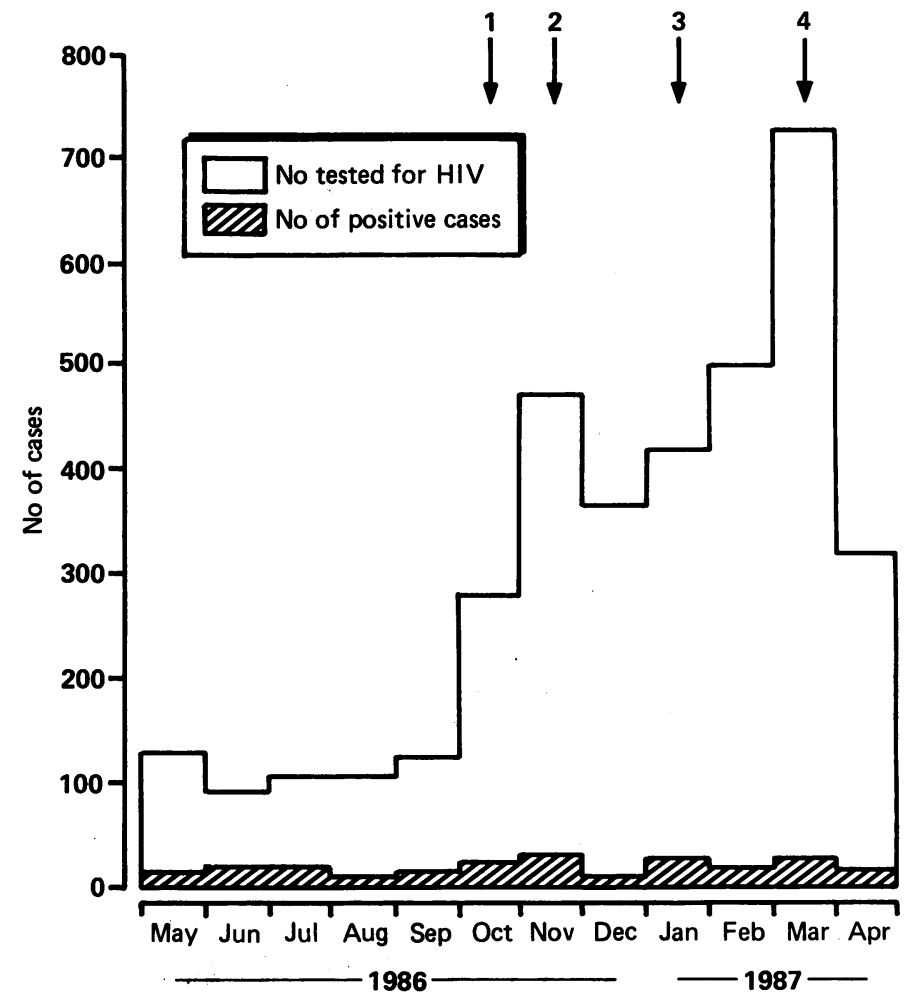

FIG 2-Temporal relation between the number of people who were tested for HIV during May 1986 to April 1987 and the start of (i) the campaign against AIDS in the popular press; (ii) the intensification of the campaign by the Department of Health and Social Security; (iii) the leaflet drop by the Department of Health; and (iv) the television campaign: AIDS week. Hatched area shows positive cases.

district. Twenty seven per cent came from North East Thames. Only 5\% (54) of those tested lived elsewhere in the United Kingdom, and nine lived outside the UK. The geographical distribution of seropositive patients $(n=103)$ was similar: $94 \%$ of the HIV positive patients lived in the four Thames regions- $47 \%$ in North West Thames and $26 \%$ in North East Thames. Fifteen seropositive patients lived in the local health district.

Of all patients tested and counselled from March to November $(n=1515)$, $52 \%$ were seen by a health adviser. The average monthly percentage varied: the percentge seen increased from $56 \%$ in March to $73 \%$ in September. A reduction to $50 \%$ and $29 \%$ in October and November occurred despite an increase in the absolute number seen. Not all patients who were counselled during the study were tested. Between March and November 1019 patients were counselled by the health advisers and $77 \%$ (782) were tested. In March $35 \%$ declined HIV testing after pretest counselling: this proportion had declined to $12 \%$ in November.

\section{Discussion}

A steep increase in the number of people requesting HIV counselling and testing at the clinic has occurred. As the number of people tested increased the proportion of positive cases decreased, suggesting the dilution of the original population by a greater number of "lower risk" people. Though a male predominance continues, there has been a rapid increase in the proportion of women tested. This was accompanied by an increase in the number of heterosexual men seen, which presumably reflects a change in the public's awareness of the potential heterosexual transmission of HIV. The homosexual subpopulation continues to have the highest seropositivity rate, while the seropositivity rate remains low in heterosexuals and women.

Overall two main groups of people who seek counselling and testing can be identified. Firstly, those who show "high risk" behaviour-that is; frequent and many sexual partners (homosexual or heterosexual) and the use of infected needles, or both. Secondly, those "low risk" people who are primarily counselled and tested for personal reassurance. Counselling and educating people from this group is also part of any national educational programme, 
though the needs of these people are different from those of people with high risk behaviour.

These changing trends suggest a change in public awareness of HIV infection and the acquired immune deficiency syndrome (AIDS). This changed attitude coincided with and was presumably largely caused by a media campaign that took place during September to November 1986. In addition to the television and radio campaign most newspapers carried daily articles on AIDS and related issues. The intensification of the government's educational programme during the week of 23 November added to this momentum. The whole issue was catapulted into the public arena and worried people turned to clinics for sexually transmitted diseases for advice and reassurance. Given the sudden increase in workload, existing services were stretched to capacity, as reflected by the saturation of the services provided by health advisers. This necessitated an alteration in counselling procedures. Furthermore, HIV testing became more popular; fewer people were satisfied with counselling by itself, irrespective of their risk factors.

The observed increase in the number of people who requested HIV counselling and testing has been sustained beyond November 1986. Figure 2 shows the number of people tested between May 1986 and April 1987. The peak that was observed in March 1987 coincided with the AIDS campaign week. The relative lower numbers seen during December 1986 and January 1987 are partly explained by closure of the clinic over the Christmas holiday and during the freezing weather respectively. The drop in numbers seen during April 1987 coincided with reduced media coverage of AIDS.

Finally, the need to collect reliable data locally, regionally, and nationally cannot be overemphasised. Information is needed not only to assess the size of the problem but also to allow us to monitor trends over time. The effects of educational programmes can also be evaluated. Confidentiality, however, adds another dimension to the logistics of collecting such data. Given the current strain on existing services, the educational programmes will continue to add to the pressure on referral centres such as the Praed Street Clinic. More resources will be needed if the full preventive role of the campaign is to be fulfilled for those who seek counselling and testing. Furthermore, since patients who attended this clinic lived in more than one region the allocation of resources and the development of services should be planned within and among regions.

We thank all members of the Praed Street Clinic and departments of virology and community medicine who helped in the preparation of this paper. We thank especially Dr J Adams, Miss A Biro, Dr Y K Lau, Professor D Miller, and Mrs J Wadsworth for their help.

(Accepted 5 fune 1987)

\title{
HIV infection: increase in public awareness and anxiety
}

\author{
C SONNEX，ANNE PETHERICK， M W ADLER， D MILLER
}

\begin{abstract}
Between the end of September and mid-November 1986 the number of patients who requested antibody testing for human immunodeficiency virus (HIV) at this department increased by over $300 \%$. This increase followed a media campaign that emphasised the potential heterosexual spread of HIV. After pretest counselling roughly one quarter of the women and of the heterosexual men decided not to be tested. The reason given most often by women for testing was previous sexual intercourse with bisexual or possibly bisexual men. Heterosexual men were most often concerned about previous casual encounters or contact with prostitutes. Of the 641 tests for HIV antibody performed during the last three months of 1986, 37 (5.8\%) were positive.
\end{abstract}

Because an increasing number of patients are attending sexually transmitted diseases clinics for HIV antibody testing staffing levels in these clinics need to be reappraised now.

\section{Introduction}

Since the first case of the acquired immune deficiency syndrome (AIDS) was diagnosed in Britain in 1981 most of the general public

\footnotetext{
Academic Department of Genitourinary Medicine, Middlesex Hospital Medical School, London W1N 8AA

C SONNEX, MB, MRCP, lecturer in genitourinary medicine ANNE PETHERICK, RGN, research nurse

$M$ W ADLER, MD, FRCP, professor of genitourinary medicine

D MILLER, MD, DIPCLINPSYCH, senior clinical psychologist

Correspondence to: Professor Adler.
}

have thought of infection with human immunodeficiency virus (HIV) as a disease of homosexuals, intravenous drug abusers, and haemophiliacs. Heterosexuals have thought of themselves as not being at risk. An initial health education campaign by the government in March 1986 seemed to have little effect on improving public knowledge about AIDS. ${ }^{1}$

Those who work with HIV infection have always seen it as being sexually transmitted and thus have been fully aware of the potential heterosexual spread. The experience from Africa has strengthened this view. ${ }^{2}$ Despite the awareness by the medical profession, however, this message has been slow to filter through to the public.

In the last part of October 1986 several television programmes and newspaper articles appeared that emphasised the possibility of heterosexual spread of HIV. Not surprisingly, many heterosexual men and women began to wonder whether previous sexual relationships might have exposed them to HIV. The sudden increase in media coverage resulted in increasing numbers of people attending clinics for sexually transmitted diseases and requesting the "AIDS virus test."

To assess the extent of this "AIDS awareness" we analysed the number of clinic attenders who requested the HIV antibody test at the department of genitourinary medicine at this hospital from the end of September to the end of December 1986.

\section{Method}

People attending the clinic who request an HIV antibody test are initially counselled by either a doctor or a health adviser. This pretest counselling entails explaining the nature of the test and the meaning of a negative or positive result. The potential risk of infection and psychological stability are considered and discussed with the patient. A note is made by the doctor or health adviser of the sexual orientation of the patient and, when possible, the reason given for requesting the test. After pretest counselling many people 